This item was submitted to Loughborough's Research Repository by the author.

Items in Figshare are protected by copyright, with all rights reserved, unless otherwise indicated.

\title{
Stimulating dynamic value: social capital and business incubation as a pathway to competitive success
}

PLEASE CITE THE PUBLISHED VERSION

https://doi.org/10.1016/j.Irp.2007.03.008

\section{PUBLISHER}

(C) Elsevier

VERSION

AM (Accepted Manuscript)

\section{PUBLISHER STATEMENT}

This work is made available according to the conditions of the Creative Commons Attribution-NonCommercialNoDerivatives 4.0 International (CC BY-NC-ND 4.0) licence. Full details of this licence are available at: https://creativecommons.org/licenses/by-nc-nd/4.0/

\section{LICENCE}

CC BY-NC-ND 4.0

\section{REPOSITORY RECORD}

Hughes, Mathew, R. Duane Ireland, and Robert E. Morgan. 2019. "Stimulating Dynamic Value: Social Capital and Business Incubation as a Pathway to Competitive Success". figshare. https://hdl.handle.net/2134/26375. 


\title{
STIMULATING DYNAMIC VALUE: \\ SOCIAL CAPITAL AND BUSINESS INCUBATION AS A \\ PATHWAY TO COMPETITIVE SUCCESS
}

\author{
Under fifth review: Long Range Planning (October 2006) \\ Manuscript reference: 06-LRP-0503-REV \\ Mathew Hughes \\ Nottingham University \\ Institute for Enterprise \& Innovation \\ Nottingham University Business School \\ Nottingham NG8 1BB \\ United Kingdom \\ Tel: +44 (0)115 8467747 \\ Fax: $+44(0) 1158466650$ \\ E-mail: mat.hughes@nottingham.ac.uk
}

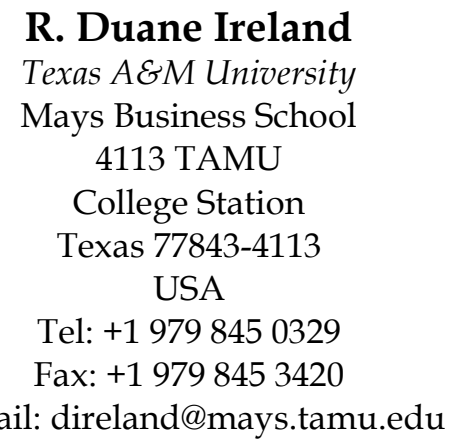

E-mail: direland@mays.tamu.edu

\author{
Robert E. Morgan \\ Cardiff University \\ Cardiff Business School \\ Colum Drive \\ Cardiff CF10 3EU \\ United Kingdom \\ Tel: +44 (0)2920870001 \\ Fax: +44 (0)29 20874419 \\ E-mail: morganre@cardiff.ac.uk
}

Please direct correspondence to: Dr. R. Duane Ireland, Mays Business School, Texas A\&M University, 4113 TAMU, College Station, Texas 77843-4113, USA. Tel: +1 979845 0329. E-mail:

direland@mays.tamu.edu

The authors thank Charles Baden-Fuller and three two anonymous LRP reviewers for their informed commentary which helped develop and improve the presentation of this paper. The authors also thank Peter Lindelöf for his comments on previous versions of this work and United Kingdom Business Incubation (UKBI) for its support in the data-generation phase of this study. 


\begin{abstract}
AUTHOR BIOS
Mathew Hughes is a Lecturer in Entrepreneurship at Nottingham University Business School. Prior to this, he completed his doctorate in strategic management and entrepreneurship at University of Wales, Aberystwyth, UK, where he also gained a first degree (with first-class honours) and Masters degree (distinction) in Business and Management. His dissertation focussed on the strategic and entrepreneurial management of business incubation to drive the strategic growth of incubating firms in a UK context. The United Kingdom Business Incubation (UKBI) further supported this research. His research interests include entrepreneurial orientation, learning, networking and social capital. His research appears in such journals as Industrial Marketing Management and British Journal of Management.
\end{abstract}

R. Duane Ireland holds the Foreman R. and Ruby S. Bennett Chair in Business in the Mays Business School, Texas A\&M University where he also serves as Head of the Management Department. Prior to joining Texas A\&M University in 2004, he held the W. David Robbins Chair in Strategic Management in the Robins School of Business, University of Richmond, and before that, the Curtis Hankamer Chair in Entrepreneurship in Baylor University's Hankamer School of Business. He is the co-author of more than a dozen scholarly books and textbooks, including two recently released books, Entrepreneurship: Successfully Launching New Ventures and Understanding Business Strategy, and the $7^{\text {th }}$ edition of Strategic

Management: Competitiveness and Globalization. He is the author or co-author of more than 70 journal articles. His work has been published in a number of journals including AMJ, AMR, SMJ, ASQ, AME, Journal of Management Studies, Decision Sciences, Human Relations, and Long Range Planning. Duane has received numerous awards for his teaching and research. A Fellow of the Academy of Management, he is currently serving an Associate Editor for Academy of Management Journal.

Robert E. Morgan is Associate Dean and the Sir Julian Hodge Professor of Marketing and Strategy at Cardiff Business School, Cardiff University. His main research interests include market-based organisational learning, strategic alliance management, and strategic entrepreneurship. His publications number over 90 , and he has consulted widely with international firms and government departments on these issues. 


\title{
STIMULATING DYNAMIC VALUE: \\ SOCIAL CAPITAL AND BUSINESS INCUBATION AS A \\ PATHWAY TO COMPETITIVE SUCCESS
}

\author{
MS\# 06-LRP-0503-REV
}

\section{EXECUTIVE SUMMARY}

Studies of business incubation tend to examine how managing the incubator can help incubating firms create value. In the past, emphasis has centred on the provision of core business services and the design of the incubator, but more recent approaches focus on the provision of a rich network through which an incubating firm can engage in collaborations. We argue that such provisions, however, dictate only the opportunities for value creation; how incubating firms choose to behave and pursue network opportunities and make use of resources and knowledge in the incubator network dictates the extent to which these opportunities can be realised and, thus, the value creation. We contend that firms' destiny lies in the hands of their combinations of strategic networking activities, and incubation outcomes do not occur because of a firm's mere presence in an incubator. By examining the incubating firm as the driver of the value creation equation, we break from extant research on incubation, which generally assigns the incubator as the creator of value.

We identify two value-stimulating behaviours (networking activities) - resource pooling activity (resource-seeking behaviour) and strategic network involvement (knowledge-seeking behaviour) - and develop a value matrix that classifies incubation into four types of outcomes on the basis of the extensive versus narrow combinations of these activities. Different combinations generate different levels of social capital, which generates unique incubation outcomes that contain varying levels of value creation potential. Enclosed incubation (narrow combinations of both behaviours) offers the least value creation potential, whereas dynamic incubation (extensive combinations of both behaviours) offers the highest. We demonstrate that each incubation outcome has merits and can be used to inform the evaluation of incubating firms and the relational strategies of their managers.

We test this four-group typology using data generated from a mail survey of young, high-technology, incubating firms. Using cluster analysis, we demonstrate that our predicted classifications fit our data well and, using additional statistical tests show that the value creation potential of each type of incubation is consistent with our propositions. We conclude with a set of implications for incubating firms, incubator management teams, public policymakers and incubator sponsors, and further research. As a preview, these implications include a matrix by which managers of incubating firms can examine why their firms experience a specific degree of value creation compared with others; a discussion of the need for incubator management teams to manage the interactions and interconnections among their portfolio of incubating firms proactively; and a new method for policymakers and sponsors to evaluate the effectiveness of incubator programmes.

Key-words: business incubation; innovation; networks; performance; small firms; social capital; start-ups; typology; value creation. 


\section{INTRODUCTION}

Creating value and stimulating business performance improvements rest at the heart of organisational decision making, regardless of the organisation's size or scope. However, young, small firms tend to find it difficult to create value because of their lack of resources, knowledge and social capital. Such 'liabilities of newness' render young firms vulnerable to complex market conditions and competition, which are the typical characteristics of modern market environments. ${ }^{1}$ Therefore, young, small firms often turn to business incubators.

An incubating firm is a new or young small firm, motivated by the liabilities of newness that chooses to seize the perceived advantageous conditions (typically co-location with other incubating firms, collaborative opportunities, provision of central services and cost advantages) of locating inside an incubator. We define a business incubator as a facility that houses young, small firms to help them develop quickly into competitive businesses. The advantage of entering an incubator lies in the opportunities for collaboration that it presents. Business incubation thus is a process of developing young, small firms into competitive businesses and can be considered an outcome of the firm's exploitation of opportunities made available to it through its presence in the incubator. Business incubation has been publicised as a successful medium to develop young firms into sustainable, competitive businesses, and the past decade has witnessed exponential growth in its adoption in economies across the world. The percentage of incubated firm survival may be as high as 80 percent, which compares favourably with typically lower success rates for young firms. ${ }^{2}$ In the face of this increased global use however, few studies have emerged to explain the strategies incubating firms should adopt to generate superior performance, so we continue to know very little about how incubating firms benefit through incubation.

Historically, research into business incubation has examined the sort of services an incubator can provide to help firms develop. ${ }^{3}$ Recent theoretical developments suggest that the likelihood of value creation increases when the incubator is structured as a strategic 
network. ${ }^{4}$ Other researchers extend this notion, suggesting that when incubating firms develop strong interactions within the network, they generate social capital, which can create substantial value, which then increases performance. ${ }^{5}$ However, the incubator provides only opportunities for value creation; the activities of the incubating firms themselves must function to realise those opportunities and create value. To date, no study of business incubation has examined how an incubating firm can seize the network opportunities presented by the business incubator to create value and increase its performance. Furthermore, extant research on business incubation tends to make two implicit assumptions: that the presence of opportunities is sufficient to incubate firms and that firms incubate equally and homogenously. In reality, they experience different incubation outcomes. Our research goal with this paper is to understand how young startup firms located in incubators maximize the benefits of being in an incubator. Accordingly, we respond to three research questions: (1) Why do incubating firms experience different incubation outcomes? (2) What are these incubation outcomes? and (3) What are the implications for value creation among incubating firms?

We address the literature gap by proposing a value matrix composed of two networking behaviours - resource pooling activity and strategic network involvementdistinguished by resource-seeking and knowledge-seeking reasons for networking. We propose that the extent to which firms adopt these two behaviours in their interactions with others in the incubator network will create different incubation outcomes that represent varying degrees of value creation. We present these outcomes in the form of a typology of four incubation outcomes, which we base on narrow versus extensive combinations of the two behaviours. Following a survey of young, high-technology, incubating firms, we use cluster analysis and support this four-group classification empirically. The outcome types explain differences in value creation and thereby offer implications for stakeholders. 
No commonly accepted definition of business incubation exists, largely because of the fragmented research base underlying it. Some researchers characterise business incubation as a model that seeks to link skills, technology, capital and know-how effectively to leverage entrepreneurial talent and accelerate a firm's development. ${ }^{6}$ This definition takes a deterministic view that a firm's mere presence in an incubator ensures its success, simply implying only the need for incubating firms to interact to cultivate value and increase performance. Thus, to date, studies have focused almost exclusively on the incubator as a creator of value. More recent definitions of business incubation, however, attempt to formalise the role of interaction. According to these definitions, the incubation of a firm improves when that young firm is located in a networked incubator, such that incubation gets defined as the process that enables fledgling businesses to create value by embedding them in a network system that provides access to an extensive network of powerful business connections. ${ }^{7}$ Others define it as a strategic, value-adding intervention system within a network context. ${ }^{8}$ We extend these interpretations to refine the definition of business incubation as the outcome of a network model of powerful business connections that enables value creation through firms establishing and exploiting interactive ties among incubating firms and networked firms. With this definition, the onus for incubation is placed on the incubating firm. We take a nondeterministic view and consider the opposite side of the value equation, namely, the part played by the incubating firm. An incubator offers only opportunities for value creation, but the extent to which that value is realised depends entirely on the extent to which the incubating firm exploits the opportunities made available by the networked incubator through its own networking activities.

A strategic network can be defined as the locus of a firm's potential and realised web of relationships, which are composed of enduring inter-firm ties that are of strategic significance to the firm. ${ }^{9}$ The management team of a business incubator constructs and frames the network and makes it available to the incubating firms. The incubator network 
therefore is a generic network available to each incubating firm, typically the set of incubating firms inside the incubator and any in-house service centres, on-site assistance organisations or outside firms brought in by the incubator's management team. The network remains the same and constantly on-hand for each incubating firm to use. Young incubating firms can draw quickly on this incubator network saving considerable time and search costs.

It is entirely possible that incubating firms may possess prior social relations or business connections before establishing as an incubating firm in a business incubator. However, relationships that incubating firms form with 'outside' firms or already had in place at the time of entry are beyond the remit of the incubator network and the scope of this study. Our interest lies with the incubator network and the incubating firm's networking activities inside this network as we wish to ascertain how firms can capitalize from the networking opportunities inside the incubator and the types of value this might create for these firms. Furthermore, given the newness, weak legitimacy and poor bargaining posture of incubating firms, they are more likely to draw from the incubator network than develop external connections. ${ }^{10}$ The co-production of value by exploiting opportunities to collaborate is the raison d'etre behind incubation and, in conjunction with the liabilities of newness, are mostly behind firms' decisions to locate in incubators. Prior external connections may demotivate an incubating firm from undertaking extensive networking behaviour inside the incubator network, thus limiting interaction and likely diminishing the value they create from opportunities made available by the incubator. In doing so, it denies itself the very possibility to realise these opportunities, suffering a strategic cost as a consequence.

The view that firms should remain individual, autonomous entities pursuing advantage against a growing stream of rival firms has become outdated. As atomistic units, firms can compete only within the confines of their own limited resource and knowledge sets. Because young firms lack the breadth of resources needed to compete effectively and lack knowledge about how to compete intelligently, they have a correspondingly weak 
scope for innovation and tend to suffer from punctuated development. Collaboration increases exposure for firms such that, through partnerships in which they draw on one another's resources or share knowledge, they can achieve more together than they could alone. By collaborating, firms can create value and increase performance, which represents the logic underpinning networked incubators.

Whilst it remains true that some firms locate in incubators purely for the benefit of location, in doing so not only does it forego opportunities to create value but it also prevents other firms in need of these opportunities from obtaining them or getting a chance to realise them. Although it is not wrong to ignore the implicit social and business network within an incubator, it is wrong to ignore the opportunity because evidence suggests that developing social capital and actively seizing network opportunities is a pathway to competitive advantage. ${ }^{11}$ It also represents unethical activity as disadvantaged firms in need of the facilities and opportunities offered by the incubator are prevented from realising this possibility. Networked incubators are efforts to discourage such behaviours because the emphasis is placed on networking not location but for those firms that do behave in such a way, they are likely to experience different outcomes from incubation than those who more actively seize the opportunities available by creating and using social capital. Indeed, incubating for location alone means the firm is denying itself the very opportunity behind incubation in the first place: the means to overcome its liabilities of newness.

When a firm develops interactive inter-firm relationships, the opportunities for value creation arise through social capital, which is created through a firm's networking activities and grows along with the extent of interactive relations. ${ }^{12}$ In essence, social capital represents a body of goodwill, a 'credential' that is developed by an actor (in this case, the incubating firm) through its actions over time and that contributes to the creation of value by affecting the conditions necessary for value creation. ${ }^{13}$ Although it is a product of interaction activity, social capital consists of structural, relational and cognitive parts. We 
focus on the relational dimension, because it forms from social interaction and represents the assets created, shared and leveraged through relations, consistent with our relational view of competitive advantage. ${ }^{14}$ These 'assets' are the actual or potential resources embedded within, available through or derived from a network of relationships, beyond intellectual capital or knowledge acquisition. ${ }^{15} \mathrm{~A}$ firm will thus orient its behaviours to seek out, on the one hand, resources, and on the other hand, knowledge.

The main objectives of networking are access to resources and acquisition of knowledge. ${ }^{16}$ The extent to which a firm pursues these objectives, and thereby develops interactive relations, determines its degree of social capital and governs the likely degree and nature of value subsequently created. Both are distinct activities, and a firm involved in one is not necessarily involved in the other. Reasons include a lack of perceived compatibility in resources or knowledge or distrust of collaboration triggered by fears of opportunism, learning races or asymmetric gains. ${ }^{17}$ Despite these concerns, research on relationships formed through networks has largely assumed that resource pooling and knowledge acquisition activities are rife among firms, though they are not. So far, we know little about the implications of lesser and greater combinations of these activities.

At this point it is necessary to distinguish between research and knowledge. Some studies have treated them synonymously but a distinction can be made in that knowledge is required to combine resources in a way that creates wealth and the fact that the behaviours needed to access resources are different form those needed to acquire knowledge. 18 Resources constitute assets possessed or controlled by the firm including physical, financial, trademark or patent, goods, services, technology (e.g., technical capabilities) and skills (e.g., marketing capabilities) and the like. Knowledge on the other hand can be of an explorative (novel, insightful) or exploitative (refining, adapting) nature and also includes know-how, know-who and experience to name but a few features. Knowledge differs substantially from resources in that knowledge requires interpretation and absorption into memory so that the 
firm learns the important information embedded in the knowledge. ${ }^{19}$ To treat them as synonymous clouds both how a firm acquires knowledge and accesses resources and how it can use them. Knowledge is far more non-specific than resources and its value must be teased out through interpretation. Networking can a help firm in its interpretation but also can aid the formation of close linkages between a firm in need of information and a firm possessing it. Given the inability of firms to neither be able to specify or account for their knowledge means it is not sensible to classify it as synonymous with resources. Thus, whilst firms can pool and draw on each other's resources through a more arms-length relationship using resource pooling activity, a firm must involve itself closely in a range of separate linkages with firms to enter into knowledge transfer by discussing, drawing on experience and interpreting information to resolve problems or challenges.

We can therefore surmise that different combinations of these networking activities (sharing and accessing resources, knowledge acquisition through active involvement) likely generate different incubation outcomes. Because firms network differently and undertake lesser or greater degrees of network activities, the extent to which they create social capital and realise network opportunities differs. As a result, incubation outcomes differ, which generates different degrees and types of value. We contend that the varying levels of these two critical networking activities generate a typology of incubation outcomes, each with a unique degree of value creation. These two critical activities are resource pooling activity and strategic network involvement, which can be distinguished by resource-seeking and knowledge-seeking views of networking, respectively.

We define resource pooling activity as the extent to which a firm is willing to pool and share its resources with others. Generally, a firm cannot access more resources than it is willing to commit. This activity represents a resource-based view of networking, in that sharing and drawing on a collection of resources enables the firm, on its own or in collaboration, to undertake a greater range of activities than it could if it drew only on its 
own limited resource base. Examples of resources that may be pooled, because they are identifiable from the specialisations of a firm, might include goods, services, technical capabilities, marketing capabilities and the like. Combining resources can result in firms undertaking joint projects that alone they may not have been able to do so. For example, a firm with technological competence in CD-ROM and multimedia production collaborated with an aerial photo company on joint projects for large commercial clients in an incubator in Bordeaux, France. Beyond joint projects, the motivation for resource-based collaboration stems from weak competitiveness and the liabilities of newness because accessing others' resources can drive richer collaborations and create value for both firms.

We define strategic network involvement as the extent to which a firm interacts with others to acquire knowledge. This activity represents a knowledge-based view of networking and requires close, repeated interactions to glean knowledge that can improve the intellectual capital of the firm. Some firms involve themselves only in relationships with one or a few firms, which results in low network involvement. Therefore, the rate at which they are exposed to knowledge is much less than that of a firm more broadly involved with more networked firms. Access to knowledge comes from discussion, enquiry and interaction and cannot be pooled because of its intangible and asymmetric properties and dependence on interpretation. Knowledge obtained through such interactions is typically exploitative, because the knowledge transferred is not new or unique. ${ }^{20}$ Nonetheless, it serves to enhance a firm's knowledge base rapidly with information with a known outcome, ${ }^{21}$ which is valuable for an incubating firm that suffers from weak knowledge reserves and the liabilities of newness. Knowledge a firm obtains from an informed firm is typically information, experience or advice on tackling business problems or challenges. A few examples of this phenomenon includes the case of an incubator in Linköping, Sweden, where each month a specific breakfast session is held where managers from tenant firms meet together with area experts in law, patent, marketing and the like to learn from one another's experience and 
insight and watch various presentations. There is also an 'idea lab' section for firms to meet to brainstorm or trade ideas and knowledge to explore avenues for problem-solving or collaboration. Another example is the MerseyBio incubator in Liverpool, United Kingdom, which has been lauded by Forrester Research for its incubator-level Innovation Network which helps incubating firms to share research together and with external organisations such as universities and medical centres who are connected through a virtual system to the network. Sharing expertise has helped firms to achieve greater parity with established rivals according to the incubator manager. A further example is illustrated in Exhibit 3 where the firm 'DNA Tech' was able to leverage its business acumen by drawing on the knowledge and experience of firms in the incubator network. Knowledge sharing is the basic reason for firms to congregate together and an incubator's network provides excellent opportunity in this regard but, it can only be realized through extensive firm behaviour in strategic network involvement.

A firm that engages in resource pooling is not necessarily highly engaged in discussion or knowledge-based interactions with other firms. Similarly, a firm willing to share and draw on the resources of others can do so with relatively less interaction compared to a firm seeking to acquire knowledge, which must interact closely with others but does not necessarily draw on resources, rendering the activities mutually exclusive. Much in the same way that knowledge and resources are separate, a firm must use resourcebased interaction (resource pooling activity) and knowledge-based interaction (strategic network involvement) as routes to explore possible symbiosis between themselves and others in the incubator network in the act of generating social capital to use to unlock value. For example, our interviews with a set of incubating firms in the U.K. illustrated how a website design and admninstration company might help a firm in the network at preferential artes to establish an Internet presence in return for marketing exposure. In doing so, resources are pooled and used but no knowledge is shared. On the other hand, a 
company engineering electronic devices had little acumen in product launch and so enquired other firms about what they did to make this process work and sought advice on ways to commercialize their technology. Knowledge was traded but no resource activity took place. Accordingly, it is important to use both behaviours to optimise value creation.

\section{VALUE MATRIX}

Social capital theory suggests that building interactive relationships in networks influences a firm's performance by varying the conditions necessary for value creation. By extension, incubating firms should pursue a relational strategy in which they focus on using network activities to instigate beneficial relationships with other firms, which can be considered external resource and knowledge holders. Social capital develops when the ties among firms are interactive and strategically important - in this case, when incubating firms utilise resource pooling activity and strategic network involvement. Assuming that mutual dependence, due to the liabilities of newness, drives firms to collaborate, the distinguishing factor responsible for incubation outcomes and heterogeneous levels of value creation must be the relative magnitude or degree to which the incubating firms choose to interact.

In Figure 1, we illustrate a two-by-two classificatory matrix of value creation potential for four different incubation outcomes, which we label the value matrix. These different incubation outcomes occur because any value to be created and accrued depends on how the firm chooses to strategically pursue incubation. Firms' networking behaviour governs the extent to which the opportunities offered by the business incubator are realised. If the magnitude of networking behaviour differs, it raises or limits social capital and thus changes the extent to which value is created.

\section{Insert Figure 1 about here}

We characterise the magnitude of resource pooling activity and strategic network involvement with two polar opposites on an interaction continuum: extensive and narrow, Extensive interaction is wide-ranging, far-reaching, comprehensive interactive behaviour in 
which the firm is highly active in pursuing, developing and managing relationships based on the specific networking activity. Narrow interaction is focused, interactive behaviour in which the firm is reluctant to pursue, develop and manage relationships, which results in limited collaboration in terms of the specific networking activity. Different combinations of the two behaviours result in different classifications of incubation outcomes. The four classes of incubation outcomes, each with its own value creation potential, are: enclosed, specialised, community and dynamic. Enclosed incubation as an outcome holds the least potential for value creation, whereas dynamic incubation offers the greatest.

The thesis behind our typology is that value creation is optimal when both networking activities are used extensively. However, an incubating firm may not automatically push such an agenda on both fronts and so we must consider why a firm experiences one incubation outcome rather than another. First, incubation outcomes may result from planned strategic choices or deliberate decisions by the incubating firm to pursue both networking activities, one activity over another or none at all. For example, a firm might conclude that its resources and operations are incompatible with others but values the sharing of knowledge and engaging in intellectual enquiries with networked firms. Second, rather than making deliberate choices for action or inaction, firms may make decisions unconsciously, non-deliberately or without planning, which leads to emergent action or inaction that likely depends on whether the incubating firm has a formal relational strategy. Third, actions have their consequences, and collaboration involves both costs and risks. For example, as a firm acquires more exploitative knowledge, the acquisition becomes increasingly less valuable and redundant, which may inhibit interaction. Moreover, firms tend to be cautious and conservative in releasing their value-creating resources and sharing their knowledge for uncertain returns that may not be instantaneous. These conditions spark concerns that may inhibit logically desirable behaviour. In other words, collaboration creates something of a paradox, caused by its inherent uncertainty. It is easy to tell firms that they 
should interact continuously, but firms understandably may be wary of the uncertainty of outcomes or risks involved, which constrains their interactions.

Managers can utilise the matrix presented herein to ascertain the possible outcomes of their own action or inaction. The matrix can inform firms of what can be achieved if they revisit their network activities and reshape their approaches to collaboration and incubation. We now discuss each combination, incubation outcome and the degree of value created to clarify the consequences of undertaking networking activities to a lesser or greater degree.

\section{Enclosed Incubation}

Enclosed incubation occurs when a firm undertakes narrow resource pooling activity and narrow strategic network involvement. That is, the firm neither attempts to share or draw on network resources to any great extent nor is concerned with developing a range of network connections to acquire knowledge. Instead, it regards success as a product of its own endeavours and minimises its reliance on others. We label this outcome 'enclosed incubation' because the firm develops from within, with few if any outside contributions. Operating as an atomistic or individual entity, the firm's locus of value creation is limited to its own resource bundle, activities and specialisations, and its performance is restricted to what it can achieve alone. By minimising its interaction behaviour, the firm significantly reduces the extent of value-creating opportunities, which in turn are unlikely to be realised. Evidence suggests that actively pursuing relations lead to greater value creation because synergistically leveraging collaborators' abilities and activities enables firms to outperform jointly what either could achieve alone. ${ }^{22}$

Various reasons might explain why firms make little or no effort to collaborate and therefore experience enclosed incubation. First, a narrow combination of resource pooling activity and strategic network involvement might be a firm choice as a result of its reluctance, distrust or fears of exploitation. If the firm wishes to protect, keep secret or shield awareness of an innovation, for example, it may deliberately avoid interaction to minimise 
the risk of exposure. Managers of incubating firms we interviewed expressed concern that the open environment of an incubator facility could compromise their secrecy and make it difficult to keep new ideas confidential. Some expressed fears that an outsider could visit and tour the facility with an open view of the incubating firms, which could compromise the secrecy surrounding innovations and business processes. Whether these fears are founded is dubious but indicates why the enclosed incubation outcome may occur as a matter of choice.

Second, the narrow combination might be brought about by a lack of understanding of the possible contributions of partnering, a lack of knowledge about how to integrate possible partners, or a lack of social capital brought on by the reluctance to interact. In essence, the firm might voluntarily or involuntarily constrain its value creation potential.

Educating firms about the value of networking could clarify that its benefits likely outweigh any negativity. Firms largely share some degree of co-dependence, because no one firm has all the resources and capabilities needed to perform effectively in modern, turbulent environments. When firms pool resources, they can understand one another's resources, which motivate collaborative efforts to create value by co-exploiting these resources. Yet many such opportunities are missed. In this sense, firms' strategic network involvement enables them to understand which firms to approach as partners and glean knowledge to advance their own activities while sharing their knowledge with partner firms. Again, many such opportunities are missed. In both cases, social capital is created only weakly, which limits value creation (see Exhibit 1).

\section{Insert Exhibit 1 about here}

\section{Specialised Incubation}

Specialised incubation occurs as an outcome when firms undertake extensive resource pooling activity but only narrow knowledge-based interactions in terms of strategic network involvement. A firm might draw on the resources of others to expand its activities and commit its own, which enables it to maximise the joint resource base between itself and 
its collaborator, generating scope to explore and exploit resources for joint projects, innovation and mutual performance increases. An example here is the digital medial firm and aerial photography firm in the Bordeaux incubator creating a new line of business by combining their joint resources, provided earlier. The chief motivation for such behaviour is interdependence among firms. Young firms must collaborate to overcome their inherent resource limitations, which threaten their survival. Resource pooling activity increases firms' opportunity space 23 to use and combine resources in new ways to create value.

The second factor characterising specialised incubation is the firm's limited strategic network involvement. These firms do not seek to interact much to acquire others' knowledge to integrate into their activities likely because they do not believe it worthwhile or possess no overt need. Thus, the firm largely ignores any cross-fertilisation of knowledge and experience. Such behaviour is likely if the firm views its activities and operations as beyond the knowledgeable scope of other firms in the network, so, intentionally or not, it isolates itself from interactions other than those with a resource-based nature. We label this outcome 'specialised incubation' because the firm shares and draws resources only to further its specialist activities. Such an approach to incubation may be due to productservice specialisation, a degree of arrogance or the perception that the knowledge available is insufficient to justify exposing its own.

Plausible reasons exist to explain why firms undertake little strategic network involvement and choose not to pursue the available knowledge. First, firms that share and draw resources can do so through an arm's-length relationship without needing to engage much further. Acquiring knowledge, however, is a social activity that requires direct engagement. Thus, interaction requirements are very different, and an incubating firm may be uncomfortable sharing knowledge with firms with which it lacks a close bond. Second, the firm may believe that its knowledge base is incompatible with, or not complementary to, the knowledge sets in the incubator network. Third, the type of knowledge that firms 
typically acquire through interaction is exploitative in nature, which means it reflects experience and information already in existence and not unique. Although it is of a known value and carries a certain outcome, the value is low and diminishes over time. Explorative knowledge, in contrast, is highly uncertain and occurs when firms interact and work together to construct or reconstruct understanding, which is more likely when firms interact closely while using their resources to experiment with outcomes (thereby employing both networking activities extensively). As a result, a firm may perceive that the knowledge and experience available is not valuable enough to risk exposing, limiting interaction.

The more a firm gets involved in the strategic network and seeks to develop close knowledge-sharing ties with other firms, the more embedded it becomes. Embeddedness enables social capital. The more embedded a firm is, the greater is its exposure to knowledge, which can improve its activities, processes and performance. ${ }^{24}$ When a firm makes little effort in strategic network involvement, it loses this opportunity to develop embeddedness and foregoes opportunities to create value, which tempers value creation.

For these reasons, we categorise this combination of networking activities as the specialised incubation outcome, a term we use to emphasise the specialised nature of the value-creation effort undertaken and the value created when the resource pooling activity is managed strategically. Much greater scope exists to create social capital than does with enclosed incubation, but the outcome remains constrained given minimal strategic network involvement. We therefore expect only moderate value creation in these conditions.

\section{Insert Exhibit 2 about here}

\section{Community Incubation}

Community incubation occurs when an incubating firm undertakes extensive strategic network involvement to seek knowledge but participates in minimal resource pooling activity. The outcome entails significant leverage in the knowledge base across a range of collaborating firms, hence the term 'community incubation'. By networking 
together, firms recognise that drawing knowledge from a cohesive network of embedded ties can help them grow and create value, that is, recognise their co-dependence.

Studies indicate that intense, repeated knowledge-seeking interaction among networking can firms generate higher levels of social capital, which triggers faster development, innovation and learning. ${ }^{25}$ The basis of this value creation is information sharing and learning, which strategic network involvement motivates. Information sharing helps incubating firms overcome their individually weak knowledge reserves to co-develop better intelligence. The more extensive such interaction, the more embedded a firm becomes in the network and the greater the likelihood that it will be exposed to different forms of knowledge, which leverages its intellectual capacity. A firm must be reciprocal in its actions to achieve strong embeddedness; otherwise, others will view it as a hollow partner, which could harm the social capital created and reduce the opportunities to be realised.

The lack of resource-based interaction reduces the extent to which value can be created, however. Because young firms inherently possess only small resource bundles, it is difficult for them to pursue multiple projects or opportunities alone. With enhanced knowledge comes the insight to explore and detect opportunities, but without sufficient resources, such opportunities cannot be exploited. ${ }^{26}$ Furthermore, attempting to exploit opportunities with too few resources is likely to be self-destructive.

Several reasons may account for this incubation outcome. The incubating firm might seek general knowledge from other network firms to build on its own business acumen rapidly using the information, experiences and understanding of others but not attempt to share or draw on resources because it lacks complementarity, fears relationship traps, asymmetric gains or making its small bundle of value-creating resources available in case doing so would undermine its present activities. As a result, a community of firms incubate together as their knowledge bases become increasingly symmetrical about exploitative experience and general understanding, and so the value created is only moderate. Without 
resource pooling, sharing and exploitation, no real new, explorative knowledge is created as a by-product, so these firms may grow together but cannot break new ground.

When firms undertake active and extensive involvement in strategic networking, incubation can become an inter-organisational product, whereby groups of firms simultaneously and jointly incubate. Such intensive interaction provides ample scope to create social capital and value, but with little resource pooling activity, this value likely is constrained. Thus, we expect only moderate value creation (see Exhibit 3).

\section{Insert Exhibit 3 about here}

\section{Dynamic Incubation}

Dynamic incubation, which represents extensive resource pooling activity in conjunction with extensive knowledge-seeking through network involvement, is the most favourable incubation outcome and should be aspired to by incubating firms. Continuous, widespread interaction among firms should produce the greatest scope for social capital than any other combination. Firms achieve this outcome because they realize that by sharing and drawing on resources, they can pursue new avenues and activities whilst drawing on the knowledge of others to learn how best to utilise these resource combinations. The value created is thus dynamic, and firms grow quickly.

With such strong social capital, opportunities for value creation are maximised. Extensive networking activity on both dimensions improves the extent to which a firm can realise opportunities and create value; specifically, strategic network involvement embeds the firm in a complex web of relationships, from which it is it repeatedly exposed to new knowledge, and the active pooling of resources with others enables the firm to pursue new projects or co-develop innovations almost continuously. Unlike the other types of incubation outcomes, no limitation restricts the extent of value creation.

Several studies find that resource-based collaborative arrangements can help generate superior business performance, create new competencies for partnering firms, 
encourage synergy and spur innovation. ${ }^{27}$ As firms repeatedly pool resources and draw on one another to develop collaborative projects, social capital is generated de facto. This social capital then facilitates access to richer resources at a more frequent pace ${ }^{28}$ and becomes selfreinforcing in creating and sustaining value.

In their study of alliances among young biotechnology firms, Rothaermel and Deeds ${ }^{29}$ find that intensive involvement in relationships fuels organisational learning, which strengthens firms' capacity for new product development. Network relationships also can operate as knowledge transmission mechanisms, so firms learn ways to exploit their own resources better. ${ }^{30}$ In conjunction with resource pooling activity, the merger of the superior knowledge and broad resource base enables firms to overcome the liabilities of newness that threaten their collective survival. Ultimately, by forging close, interactive ties, firms can leverage knowledge and resources which help them not only achieve parity with established competitors but also develop new ways of overcoming competitive threats. In summary, we expect that the significant social capital created through this particular combination of behaviour will generate the greatest value creation potential (Exhibit 4).

When a firm pursues a network relationship strategy based on dynamic incubation, it places itself in a unique network position from which it can draw on partners' knowledge and combine it with its own to develop new intelligence and generate substantial value for both. Simultaneously, it can draw on the resources of others so that both firms can actively generate new combinations and bundles to pursue new activities jointly, realising rich opportunities to create substantial value. Yet, despite the persuasiveness of this outcome, it remains a rarely achieved pinnacle. Part of the problem lies with uncertainty. To achieve this level of social capital and value creation, an incubating firm must abandon its comfort zone and be willing to make its value-creating resources and knowledge available to potential partner firms. The uncertainty of return and the risk associated with openness can render the firm inert. Arguably, the management team of the incubator should encourage 
collaboration and aid the portfolio of incubating firms to achieve dynamic incubation. Incubator management teams are in a unique position to act as relational brokers and signposts, so the firms within the incubator are encouraged to collaborate rather than seek out relations of their own volition. We illustrate this point in Exhibit 5, which shows how incubator management can help secure outcomes for a set of incubating firms.

Insert Exhibits 4 and 5 about here

\section{SUMMARY OF RESEARCH METHODOLOGY}

\section{Insert Table 1 about here}

A thorough, detailed explanation of the research method can be found in the appendix. Table 1 details the variables, how they were measured and shows the descriptive characteristics of the sample of firms who responded to our survey. Briefly, using the United Kingdom Business Incubation (UKBI) directory as a sample frame, we made a census of all 143 high technology incubators in the U.K., sampling their firms to create a database of 1000. A mail questionnaire was sent to the Managing Director of each incubating firm. We received 211 responses. Tests for non-response bias (extrapolation method) and common method variance (Harman one-factor method) produced no concerns. Scales were obtained from existing studies where possible and adapted. Tests for scale reliability (Cronbach Alpha) and validity (item-total scale correlation) showed all were within conventional limits. Cluster analysis (using hierarchical clustering method) was then performed to test the conceptualisation. Four groups were created consistent with our typology. Significant differences existed between the groups of incubation outcomes. We used regression to examine value creation potential on different value dimensions. Groups exhibited different degrees of value creation as anticipated (see Table 2 and Table 3).

\section{Insert Tables 2 and 3here}

These results reveal several significant differences among the groups across the value dimensions, and we conclude that the data support our contention that business incubation 
produces outcomes that differ according to the intensity of resource pooling activity and strategic network involvement. Therefore, the different degrees to which the two valuestimulating networking activities are adopted heterogeneously affect the extent of value creation by synthesising different incubation outcomes. These findings support our claim that the behaviour of incubating firms determines their value creation by dictating the extent to which network opportunities are realised and translated into value.

\section{RESULTS AND DISCUSSION}

In every case, the mean scores of dynamic incubation across the value dimensions are superior to those of enclosed incubation. The scores also show that specialised incubation, community incubation or both are superior to enclosed incubation on almost every occasion, with the exception of radical innovation, in their mean scores across the value dimensions. Moreover, dynamic incubation achieves a consistently superior mean score across the value dimensions compared with specialised and community incubation.

The F-ratio reveals significant differences across the groups along the value criteria, meaning that to different degrees, each group explains changes in the value dimensions. The strongest effect occurs for competitive ability development and competitive performance. The Scheffé test results identify the nature of inter-group differences in value creation potential; namely, dynamic incubation is the superior business incubation outcome that maximises value creation potential for the firm and demonstrates significant superiority across four of the five value dimensions. Dynamic incubation is superior to all in terms of achieving higher competitive performance and superior to enclosed and community incubation in achieving competitive ability development. It also demonstrates a better capacity to engender radical innovation than either specialised or community incubation outcomes and process innovation relative to enclosed incubation. Consequently, our proposition that dynamic incubation is the ideal business incubation outcome is supported. 
Our proposition that enclosed incubation has the least value creation potential for incubating firms also is supported. Although it has a better mean score on radical innovation than specialised or community incubation outcomes, according to the Scheffé test, enclosed incubation is consistently inferior across the remaining value dimensions. Specialised and community incubation prove moderate in the value created for incubating firms, as we predicted, in that both are consistently weaker than dynamic incubation but consistently superior to enclosed incubation. This finding supports the hierarchy implied in our matrix. Moreover, neither specialised nor community incubation is inherently superior to the other; neither shows any relative superiority across the value dimensions. This finding again reaffirms our proposition that, despite being products of a contrasting mix of networking behaviours, they remain incapable of creating more than moderate value. One cannot create more value than the other because both are inherently constrained.

The final element of the results is the apparent non-finding with respect to technical innovation. We find no significant differences among groups on this value dimension. Despite the different mean scores, we conclude that no incubation outcome type is inherently superior to another in terms of technical innovation. An explanation might be that technical improvements require networking with technical experts or firms with specialist knowledge or resources. This highlights the importance of complementarity among firms in the incubator network. Also, it suggests that incubator managers need to take care in selecting who should be part of this incubator network. This is not to say that such innovation will never occur. In our case exhibit (3) on DNA Tech, our interviews with that firm revealed that collaboration with a bioscience firm yielded new ideas to refine and apply their DNA testing technology. This led to additional novel applications. Anecdotally there is evidence that such innovation occurs, but it would appear from our result that no specific strategy can be used to unlock it. It is of course plausible that a different set of network behaviours may be more productive in this regard. More research is thus needed. 
The data analysis demonstrates that our propositions hold and the typology is valid. The extent to which the two networking activities are utilised creates different incubation outcomes. Business incubation can stimulate multiple forms of value for firms that improve their ability to compete, develop innovations, achieve better firm performance and overcome the liabilities of newness but the richness of the value created depends on the mix of the two networking activities and the extent to which they induce social capital. Dynamic incubation is the ideal outcome because it optimises value creation for incubating firms.

Our findings demonstrate the differences in value created through incubation when firms seize opportunities differently. Although the mantra 'don't go it alone' has existed among network research and small firm strategy for more than a decade, the effects of undertaking networking activity to varying degrees have largely been ignored. In practice, networks rarely are exploited to their fullest. We highlight the merits of each incubation outcome and explore how cooperation can create different value. Our results demonstrate the potential gains of a formal relational strategy of intensive interaction, over and above those of an ad hoc approach to interaction or, for that matter, incubation. We thus transcend the plethora of multivariate studies that simply note that more of one activity is associated with more of a prescribed dependent variable.

\section{CONCLUSIONS AND IMPLICATIONS}

We have sought to develop a typology that can explain how an incubating firm can best create value through business incubation and increase its performance. We shed light on why incubating firms experience different incubation outcomes, which can explicate how incubating firms develop. Our interest in incubating firms as the drivers of the incubation equation differs markedly from extant studies, which are replete with assessments of incubator services and support. In our view, incubating firms hold the keys to growth, in that their actions (or inactions) lead to varying degrees of value creation. We adopt a social capital view of incubation to differentiate the extent of value creation and illustrate its 
dependence on the social capital generated through alternative combinations of extensive or narrow networking activities with other firms. Our argument is based on the notion that incubating firms choose, whether deliberately or otherwise, to behave in ways that enable them to seize network opportunities and make use of networked resources and knowledge. Thus, value-creation potential depends on how extensive the interaction of an incubating firm is with others, based on resource-seeking and knowledge-seeking behaviour.

Our empirical findings support the predictions held in our matrix but there are limitations. First, we generated data from a cross-sectional study, which reduces the strength of our causal inferences. It was not feasible to collect logitudinal data from the type of firms studied because such a design would have introduced extraneous sources of variance. We took steps in our methodology to overcome this weakness and, in acknowledging studies that use a similar design to examine such relationships, we are confident that our findings are robust and contribute to the examination of business incubation. Second, we restricted our analysis of networking behaviours to two and take only resource- and knowledgeseeking views of networking. Other important behaviours may change or reinforce the nature of our typology. Thus, we advocate further research into this matter. Third, we did not take into account possible contextual variables that might influence the typology and its relationships, such as the nature and make up of the incubator (although we control for it in sample construction) or the role of incubator management in forming linkages among firms.

\section{Implications for Managers of Incubating Firms}

Business incubation offers a promising means to alleviate the liabilities of newness. However, the type of incubation outcome and the value created depends crucially on how the incubating firm behaves. For high value creation, incubating firms must embrace network relationships, but the value created still depends on the degree to which they use networking activities. It is insufficient to participate lightly in the activities; they must be applied extensively. Nonetheless, each incubation outcome has its merits. Because modern, 
complex, hostile competitive environments make it unlikely that young firms possess sufficient resources and knowledge to compete against established competitors, they must take some steps toward collaboration and accept its risks.

Managers can use our typology to understand how their firms incubate, how they are likely to develop, why they are performing in certain ways and why they may be doing better or worse than other incubating firms. To improve performance and create value, incubating firms must develop social capital and use that capital as a foundation for continuous, intense and interactive collaborations with other firms. Through a carefully constructed relational strategy, managers can manage social capital actively, and thus their firms' incubation, to reach a desired outcome. Firms should behave strategically by being willing to make the firm's small bundle of value-creating resources available to other firms with a view toward sharing and drawing on this resource pool to co-develop new combinations and pursue new projects. Also, firms must participate widely in knowledgeseeking and sharing network relationships and immerse themselves in close interactions. In doing so, the firm becomes embedded in the core of that network, which will expose it to rich knowledge that can be used to improve its activities. For these activities to generate social capital, firms must reciprocate in sharing their knowledge and resources and work to bring participants into their activities so that collectively they benefit from the interaction.

We appreciate that collaboration is not inevitable and that firms network to varying degrees; thus, managers must assess the extent of their networking activities to determine if it is merely sufficient or enabling them to realise the value that networks can provide. Young firms are co-dependent for success and can achieve much more together than separately. A detailed analysis of the firm's relational strategy is necessary to diagnose ways to improve.

\section{Implications for Incubator Management Teams}

The value matrix can be used as an analytical framework to identify how value might be created or constrained for the portfolio of incubating firms and so identify ways to 
encourage and facilitate collaboration among firms. Incubator management teams are in a unique tertius iungens position as relational brokers that can link firms together. ${ }^{31}$ This powerful position is, for the most part, unexplored in incubation research. Our preliminary field research indicates that some managers view such a role favourably, whereas others question the extent to which brokers can link disparate firms. We believe it is a valuable role; incubating firms may deliberately or unknowingly limit their networking behaviours because of undue fears. Incubator management teams should take a proactive approach to encourage and maintain interaction and collaboration among firms, to help them get the best out of one another and realise incubation opportunities. By coordinating interactions, incubator management can help ensure that firms achieve dynamic rather than enclosed incubation. Moreover, incubator management teams should consider issues of strategic complementarity when developing the portfolio of incubating firms and network members. They must carefully assess the potential for incubating firms and network members to create meaningful relationships as a foundation for creating value. Low complementarity might limit interaction among firms because they would view themselves as incompatible.

\section{Implications for Policymakers and Incubator Sponsors}

This study raises implications for assessing the effectiveness and efficiency of incubation and examining the deliverables of incubator programmes. Although we do not contest that an incubator can contribute to value creation, we posit that the incubating firms themselves are equally, if not more, in control of their own destiny and responsible for what they gain from incubation. Presence in an incubator alone does not result in success. Managerial action or inaction is a determinant of the success of incubation and thus of the incubator. Policymakers and incubator sponsors should not rush to judgement on the perceived under-performance of an incubator programme until they have considered the role of the incubating firms. This warning reinforces the call for incubator management teams to take a proactive approach to managing linkages among firms in the network. 


\section{Implications for Researchers}

Additional research into business incubation is needed because our results raise several questions regarding the value-creation process. First, business incubation research lacks sufficient conceptual and empirical development, in terms of creating value from the view of the incubating firm. Research has focused almost exclusively on the organisation, design and services of the incubator. Second, we need to understand the role of firm behaviour in incubator networks. We put forward two possible activities in this study, but others also warrant consideration. Moreover, we need to understand why firms do not automatically use such behaviours and appreciate the consequences of different applications of networking activities. Until very recently, existing research has tended to ignore the role of the magnitude of behaviours in the formation of social capital. Third, we do not consider the role of complementarity among firms, though we realise that it may encourage or discourage interaction. Without complementarity, firms within a network may share little strategic relevance, which limits their interaction. Fourth, a comparison of the value of incubator networks versus externally built networks would shed light on how incubating firms create value. Fifth, our level of analysis in this work was the incubating firm since we were concerned with what networking behaviours, and subsequently relationship strategies, a firm could employ to create value from opportunities in the incubator network. But, it is possible that the incubator itself may impinge on this relationship. Future research would benefit from studying whether the type of incubator itself affects the scope for incubating firms to create value. Nonetheless, the need for incubating firms to spearhead interaction to create value nonetheless remains the same. Sixth, there is a dearth of research devoted to factors that might jeopardise or challenge social capital, compared with its uses and benefits. We suggest this represents a key area of concern for researchers. 


\section{APPENDIX 1: RESEARCH METHODOLOGY IN DETAIL}

\section{Data Generation: Sampling}

Our sampling frame was the United Kingdom Business Incubation (UKBI) directory, selected because it represents the most comprehensive reference for incubators in the U.K. Moreover, inclusion in the directory requires meeting several criteria, including having in place a generic incubator network, as previously defined. We are confident that incubators in the directory fulfil our definition of an incubator. In turn, we believe networking issues are relevant to these incubating firms. We further scrutinised the sample frame and found that approximately 73 percent of incubation programmes in the directory catered to hightechnology incubating firms. Consequently, we chose to focus on this majority.

From the UKBI directory, we identified 196 incubators. Each listed incubator was carefully examined to ensure that it was of a high-technology disposition to minimise sampling error. We then built a database of all high-technology incubating firms located in the relevant listed incubators. We adopted a liberal view of 'high-technology' firms in line with other studies that characterise high-technology firms as employing highly skilled employees, emphasising research and development, utilising new technology that renders existing technology vulnerable to obsolescence, exploiting new technologies in production, having a high level of expertise necessary for operations and employing innovation frequently. ${ }^{32}$ We identified 17 bioscience, 11 computing and digital media, 53 general, 114 high tech, and 1 laser engineering. We removed the general incubators from the sample and thus sampled 143. A random sampling method generated a sample of 1,000 incubating firms to be surveyed. We further verified that firms were consistent with our definition to minimise sampling error. In the end, this study became a census of all high technology incubators in the UK at the time of the study. All 143 were used in the end to construct the subsequent sample of 1000 incubating firms which we surveyed.

\section{Data Generation: Survey Administration}


A mail survey, which adhered to the principles of the tailored design method, was administered to generate the data. ${ }^{33}$ This method includes the use of pre-notification correspondence, questionnaire package, and first and second follow-up reminders. Recommended practices regarding questionnaire salience, length, return postage, anonymity guarantees and university sponsorship were also integrated into the survey implementation. We received 211 usable responses. The managing director of each incubating firm was selected as key informant. Because the issues in this study are strategic in nature, the key informant had to come from a senior management level to respond in a knowledgeable manner. Top-level managers, such as managing directors, are the principle sources of information about strategic activities and factors that involve the firm as a whole, possess knowledge of internal and external issues to the firm, have similar responsibilities regardless of firm size or scope and are in the best position to provide key insights into firm practices and outcomes, especially in small, entrepreneurial firms. ${ }^{34}$

Given the small size of the firms we investigate, it was not feasible to acquire multiple respondents. But, because one senior manager tends to have dominant control over such firms, a key informant approach is methodologically appropriate. Nevertheless, we tested for common method bias by employing the trusted Harman one-factor method. 35 Principal components analysis of all measures used produced a five factor solution with eigenvalues greater than 1.00. According to this method, a single factor solution indicates problematic common method bias. Since several factors were extracted and the first factor accounted for less than half of the total variance, and no general factor was extracted from the unrotated factor structure, common method bias was not a matter of concern within our data and did not alone explain any observed relationships between our measures. We tested for non-response bias by using the Armstrong and Overton 'Extrapolation Method'. ${ }^{36}$ No significant differences $(p \leq 0.05)$ between early and late respondents were found, indicating that non-response bias was not a problem affecting the dataset. 


\section{Measures}

We pre-tested the survey instrument with groups that could offer expert insights into the content validity of the questionnaire. We carried out presentations, discussions and correspondence with other academic researchers who have expertise in the issues contained within our study. Our second pre-test activity included face validity checks that assessed the degree to which the scales appeared relevant and acceptable to survey participants, which we performed with managing directors at a handful of incubating firms. Understanding, interpretation and comprehension of the questions by subjects, combined with an appraisal of survey participants' willingness and ability to respond to the questionnaire, were considered. We also consulted senior advisory personnel at UKBI, regional development agencies and other non-governmental organisations. Suggestions for improving the survey instrument were offered and led to several amendments.

The scales used to measure the relevant constructs were adopted from the literature when possible but in many instances had to be constructed. We examined conceptual research on relationships that considers the role of networking in incubation and creating value and generated definitions of each construct to guide our scale development. Following existing studies of social capital, ${ }^{37}$ we developed measures for resource pooling activity and strategic network involvement as networking activities that synthesise its relational component. Social capital thus is a product of these behaviours. Value creation was characterised by increases in innovation, competitive ability and competitive performance.

Measurement scales were anchored 'strongly disagree' (1) and 'strongly agree' (7), and increasing agreement represents increasing magnitude in the measures. We measured resource pooling activity with items drawn and developed from Hansen et al., Sarkar et al. and Sivadas and Dwyer, ${ }^{38}$ which we built upon to obtain a battery of measures that detected the extent to which an incubating firm would be willing to pool, share and draw on resources provided by firms in the incubator network. We measured strategic network 
involvement by developing scales that asked managers to be candid about the degree to which they interacted with firms in the incubator network, specifying knowledge-seeking behaviour in the lead to the question. We used studies by Hansen et al., McEvily and Zaheer, and Sarkar et al. to guide this development. ${ }^{39}$ Scales for innovation were developed using Garcia and Calantone, Rindfleisch and Moorman and Song and Parry. ${ }^{40}$ Scales for competitive ability development and competitive performance were new but informed by concepts in the incubation literature.

All items were inserted into principal components analysis using Varimax rotation with an eigenvalue criterion of 1.00 to generate robust factor solutions. We subjected the factor structures to tests of content and face validity to ensure that they were theoretically valid and conceptually intelligent. No problems were detected. Scale reliability was tested for by examining the Cronbach's alpha of the items that form each construct. Scale validity was tested by calculating item-to-total scale correlations, which appear in Table 1 . The Cronbach's alphas are well within conventional limits (greater than 0.7), and item-to-total scale correlations are all high and in the expected direction. ${ }^{41}$

\section{Cluster Analysis Method}

Cluster analysis allows a sample of firms to be grouped on the basis of multiple variables to define clusters in which the statistical variance among grouped firms is minimised whilst variance between groups is maximised. In this study, we use resource pooling activity and strategic network involvement to discriminate among firms and generate different groups of incubation outcomes. We then subject these groups to multivariate and univariate analyses to determine their differences on value-creation dimensions. To identify groups, we followed rigorous cluster analysis guidelines. ${ }^{42} \mathrm{We}$ selected a hierarchical clustering method because of its effectiveness in generating compact spherical clusters. ${ }^{43}$ This method enabled us to identify groups of firms with similar outcomes, as characterised by their relative degrees of resource pooling activity and strategic 
network involvement, and thus determine if there was a match between the empirically derived groups and our theoretically defined incubation outcome types.

The final cluster solution created four groups of incubation outcomes, consistent with our theoretically derived conceptualisation. Significant differences were computed among these incubation outcome groups (clusters) across the two networking activity dimensions we defined, so we labelled them identically to the conceptualisation presented in the value stimulant matrix: "enclosed incubation" $(n=70)$; "specialised incubation" $(n=$ 47); "community incubation" ( $n=48)$; and "dynamic incubation" $(n=37)$. Table 2 contains the results of the cluster analysis.

\section{Incubation Outcome Type (Inter-Group) Differences}

Multivariate analysis of variance (MANOVA) was performed to test the null hypothesis of no simultaneous incubation outcome type differences based upon several value dimension variables (radical innovation, technical innovation, process innovation, competitive ability development and competitive performance). We can reject this null hypothesis $($ Wilks' Lambda statistic $=0.54 ; F=8.48 ; p \leq 0.001)$ (Table 3). This denotes high discrimination between the four incubation outcome groups. We identify the contribution of each value dimension variable to the incubation outcome differences by analysing potential univariate effects. This analysis reveals that group means differ across the value dimensions, which indicates that incubation outcome types possess different value-creation potential, as we predicted. We use an ANOVA with post hoc analysis (Scheffé test) to investigate the extent to which significant differences exist among the groups in relation to each value dimension, as we show in Table 3. These results reveal several significant differences among the groups across the value dimensions and therefore support our contention that different combinations generate different incubation outcomes, as well as that they heterogeneously affect the extent of value creation through business incubation. 


Exhibit 1: Enclosed incubation as a result of choice and circumstance
'E-Invoices'* was established in early 2002 by two young entrepreneurs with a track record
of setting up successful e-commence businesses. The firm developed an intelligent and
sophisticated programme package that enables small businesses to exchange invoices
electronically, securely and rapidly with midsized and large organisations using existing
accounting software. In discussions, their managing director stressed that "I have little
knowledge of who comes in or out [of the incubator network] and more should be made to introduce
businesses and maintain high interaction.... We have one customer here and we mostly possess our
own skills, competencies and resources and so we don't need to utilise anyone else here - primarily
due to the fact that we don't see a suitable source of resource or capability present here." In addition,
he stated, "I feel that the network here can provide appropriate assistance but we're not motivated to
seek it out. To be honest, the network is not strategic or formal enough for liking" and "The skills and
ability for success has to primarily be inside our business."
E-Invoices experienced enclosed incubation because it believed that firms in the incubator
network could not meet its competitive needs in terms of either resources or knowledge and
therefore undertook little interaction. The firm was somewhat reclusive in the incubator,
according to discussions with others, despite being a high-profile firm due to its successes.
At times, the firm came across as very self-assured of its future. E-Invoices shows that
enclosed incubation can happen by choice or because of perceptions of circumstances or
conditions. The firm appreciates what networking can offer but is not motivated to network
due to its perceived superiority and incompatibility.
*The name of the incubating firm has been changed to prevent identification, in line with the
assurances of anonymity given to the managing director.




\section{Exhibit 2: Moving toward specialised incubation}

DDI Ltd*, a medical device company developing drug delivery and drug infusion products for people with intensive and chronic care needs founded in 2002, is one firm that has made a lot of use of on-site shared resources but also has drawn heavily on the resources of the engineering and clinical departments of a local university partnered into the incubator network. It uses the links to develop new means of exploiting its primary technology.

A second company at the incubator, LightStream Ltd* formed in 2001, has equally benefited from being able to create powerful linkages with the local university interconnected nto the incubator network. Its products centre on the use of its powerful LED lighting technology in medical and other niche markets. It collaborates very closely on research and development activities to develop further sustainable products that can increase the firm's market share.

The incubator they are located in is an innovative facilitate designed to encourage technology-based collaboration but is it still in the process of forming strategies to help its firms succeed together. Although they are moving toward specialised incubation, they are doing so somewhat haphazardly rather than encouraging it.

*The name of the incubating firm has been changed to prevent identification. 


\section{Exhibit 3: Community incubation and its value for one business}

'DNATech'* was established in 1999 to take advantage of the expected growth in demand for automated DNA testing devices and has since experienced increasing demand for its products. The firm was created by two entrepreneurs with a wealth of experience working for a large medical instruments organisation. The firm now focuses on the medical testing instrument sector and enjoys an excellent reputation amongst its global customers. Chief products are DNA testing machines and automated liquid handling robotic instruments for the biotechnology industry. During discussions with the managing director about the value of incubation, the following key points emerged: "Having others around helps and is great when you need to find something out quickly and we've learned so many things from other businesses here-you don't feel so isolated." "But sometimes you feel knowledge is at risk-sometimes it's just too open here and people can just walk in and tour and learn from you. Competitors could easily come in and out of here and walk past and think 'that could be useful'." "We've learned very quickly what it takes to compete and how to compete [in an innovative, competitive marketplace] and that's why we're already on the second generation of our core product. Being in the incubator [network] has helped us achieve that." "A smaller company needs to learn quickly and improve itself and its products, and I believe it's helped us in this way to be here." "[In terms of resources] We are cooperating closely with one business in the incubator to combine our skills and bringing them together to work on a new project ... but we are in a niche market so the other firms don't really fit our resource requirements."

"We can mingle with other businesses... There should be more 'mingling' for example so that people share more problems and help each other more ... but when you're running a business, sometimes you tend to do it with 'blinkers' on but common problems could be solved together but confidentiality and intellectual property [can be barriers]." "The incubator provides a feeling that there are a lot of businesses in the same boat as you... you find that other businesses have the same issues as you." "We know we can speak with other firms ... but you need awareness of those that are here."

DNATech held its incubation community in high regard and benefited greatly from the knowledge available. The entrepreneurs behind the firm largely lacked business knowledge but rapidly acquired it and leveraged their ability to compete through strategic network involvement activity. The manager reported to us increases in his acumen of marketing methods and handling customers for example. Since he previously had an engineering background, he expressed clearly how valuable the ability to draw on the knowledge of others had been in terms of running a business. They rarely collaborated in resource terms, due to what they perceived as compatibility barriers with other firms. Nonetheless, they benefited greatly from community incubation through knowledge acquisition.

*The name of the incubating firm has been changed to prevent identification, in line with assurances of anonymity given to the managing director. 


\begin{tabular}{|c|}
\hline Exhibit 4: Working toward dynamic incubation \\
\hline $\begin{array}{l}\text { 'Fire Technologies'* is a leading provider of bespoke software development services, } \\
\text { providing custom software solutions and IT consultancy services. It serves many different } \\
\text { businesses, from local and start-up enterprises to multinational corporations and large } \\
\text { public sector organisations. Founded in 1999, the firm has consistently delivered high- } \\
\text { quality solutions and services and developed a strong national reputation as a reliable and } \\
\text { trusted solution provider. From its founding, the firm has been profitable and debt-free, } \\
\text { demonstrating its stability and sustainability. In discussions with the managing director, the } \\
\text { main discussion points were as follows: "We've been able to rely on other businesses here, } \\
\text { especially through accessing resources and advice and building synergy through relationships with } \\
\text { other businesses... Cooperation with close [compatible] businesses has been really important to us } \\
\text { and how we can compete. We're working closely with these businesses to improve our [product] } \\
\text { offering." "Being close to others and networking has helped us to get more experience and learn } \\
\text { things, and this place has been a major help to our business." "We're closely working with some } \\
\text { members but others we know little to nothing of... They've been valuable to us and the synergy with } \\
\text { being so close to these key partners has really helped our business ... but ... there's not much } \\
\text { facilitation within the centre for bringing people together for networking and more could be done here } \\
\text {... we need more encouragement for inter-change and exchange of business opportunities. An } \\
\text { Intranet, monthly tenant meetings, newsletters and so on would be a good way to spark network } \\
\text { interest. Managers should take a more active role [in that regard] ... and in coordinating } \\
\text { communication." }\end{array}$ \\
\hline $\begin{array}{l}\text { Fire Technologies has demonstrated tremendous performance since its inception, which, as } \\
\text { the quotes testify to, is partly due to the dynamic incubation it has been experiencing. Yet } \\
\text { the managing director offers some criticism of the role of incubator management, suggesting } \\
\text { that a proactive approach to facilitating networking would be desirable. }\end{array}$ \\
\hline *The name of the incubating firm has been changed to prevent identification, in line with the \\
\hline
\end{tabular}




\section{Exhibit 5: NVP Brightstar as an example of an incubator working toward ensuring dynamic incubation for its incubating firms}

Brightstar was the corporate incubator for British Telecom (BT) in the United Kingdom but in March 2003, in partnership with New Venture Partners (NVP), Brightstar was spun out to form NVP Brightstar. It retains close collaboration with BT and continues the tradition of both its parents in the commercialisation and entrepreneurial approach to the exploitation of corporate intellectual property, strengthened now by a portfolio of firms, and direct access to BT's corporate research labs and offices in UK and USA. It focuses on developing an entrepreneurial environment that gives firms the strategic support and opportunity to bring new technologies and innovations to market effectively and efficiently. Adopting a hightechnology focus, Brightstar consists of entrepreneurs from the outside community that approach it with innovative and viable proposals, as well as staff members from within BT who have a proposal for an innovative business. A primary basis of the Brightstar incubation model is a vast network of strategic partners that can provide key services to incubating companies, as well as access to knowledge, expertise and even patents. The key to the sustained success of all involved is the maintenance of a mutual circle that works to improve and enhance the processes, skills, competencies and knowledge of the participants. The sharing of expertise, knowledge and competencies serves as a chief strategic facet. Autonomy is given to the incubating firms, particularly the freedom to evolve and explore new avenues. This freedom can create a state of continuous flux within the incubator as a whole, but it serves to re-emphasise the innovative nature of the companies and the environment promoted within the incubator. 'Surgeries' (meetings between business experts and the incubating firms) and visits by BT and strategic partners are conducted to provide proactive and continued support to promote the competitiveness of those involved.

Source: Developed by the authors from material available at www.btbrightstar.co.uk, discussion with Gopal Kutwaroo, Senior Network Manager at BT during 2001, and other publicly available material. Information also obtained from www.atadastral.co.ul/companies/nvp_brightstar.asp 


\begin{tabular}{|c|c|}
\hline Scale Composition & $\begin{array}{l}\text { Alpha/Item-to- } \\
\text { Total Scale } \\
\text { Correlation } \\
\end{array}$ \\
\hline $\begin{array}{l}\text { Resource Pooling Activity (RESPOOL) } \\
\text { Participants provide vital inputs we find difficult to obtain elsewhere. } \\
\text { Participants share a level of mutual dependence to achieve stronger competitive performance. } \\
\text { Accessing the inputs of other participants is important to our performance. } \\
\text { Operating in the centre/park allows our business to access a pool of inputs quickly and timely. } \\
\text { Operating in the centre/park affords our business access to inputs at more competitive terms than } \\
\text { were we not members. } \\
\text { Inputs brought into the centre/park by each participant are valuable for each other. } \\
\text { (Sources: Hansen et al.; Sarkar et al.; Sivadas and Dwyer) }\end{array}$ & $\begin{array}{l}0.93 \\
0.90 \\
0.89 \\
0.86 \\
0.87 \\
0.83 \\
0.82\end{array}$ \\
\hline $\begin{array}{l}\text { Strategic Network Involvement (SN_INV) } \\
\text { We regularly try to involve a number of business network organisations in the course of our } \\
\quad \text { business. } \\
\text { We find it necessary to involve ourselves in a business network. } \\
\text { We regularly attempt to obtain assistance from network businesses available through the } \\
\quad \text { centre/park. } \\
\text { We regularly participate in networks available through the centre/park. } \\
\text { (Sources: Hansen et al.; McEvily and Zaheer; Sarkar et al.) }\end{array}$ & $\begin{array}{l}0.86 \\
0.82 \\
0.82 \\
0.86 \\
0.87\end{array}$ \\
\hline $\begin{array}{l}\text { Radical Innovation (R_INNOV) } \\
\text { We are responsible for 'new-to-the-world' innovations. } \\
\text { We are responsible for new to the market/industry innovations. } \\
\text { We have introduced products that are among the first of their kind in the market. } \\
\text { Our products rely on technology never before used in the industry. } \\
\text { We develop product technology new to the business. } \\
\text { We have generated a new competitive environment. } \\
\text { (Sources: Garcia and Calantone; Rindfleisch and Moorman; Song and Parry) }\end{array}$ & $\begin{array}{l}0.90 \\
0.90 \\
0.88 \\
0.85 \\
0.81 \\
0.72 \\
0.72\end{array}$ \\
\hline $\begin{array}{l}\text { Technical Innovation (T_INNOV) } \\
\text { We are responsible for causing improvement/modification of technology in use elsewhere in the } \\
\quad \text { industry. } \\
\text { We have played a part in the modification of existing technology used in other industries. } \\
\text { (Sources: Garcia and Calantone; Rindfleisch and Moorman; Song and Parry) }\end{array}$ & $\begin{array}{l}0.74 \\
0.89 \\
0.89\end{array}$ \\
\hline $\begin{array}{l}\text { Process Innovation (P_INNOV) } \\
\text { We develop new ways of conducting business activities. } \\
\text { We drive improvements in the ways in which we conduct our business. } \\
\text { We generate administrative processes new to the business. } \\
\text { (Sources: Garcia and Calantone; Rindfleisch and Moorman; Song and Parry) }\end{array}$ & $\begin{array}{l}0.84 \\
0.90 \\
0.85 \\
0.86\end{array}$ \\
\hline $\begin{array}{l}\text { Competitive Ability Development (CADEV) } \\
\text { We have developed many new skills unexpectedly. } \\
\text { We are able to do many things we initially thought would be beyond the reach of our business. } \\
\text { We have experienced a growth in our resources and capabilities. } \\
\text { Our cost base is much less than had we 'gone it alone'. } \\
\text { (Sources: Hansen et al.; Kambil et al.) }\end{array}$ & $\begin{array}{l}0.71 \\
0.75 \\
0.76 \\
0.74 \\
0.70\end{array}$ \\
\hline $\begin{array}{l}\text { Competitive Performance (COMPPERF) } \\
\text { We are better equipped to interact with our competitive environment than had we 'gone it alone'. } \\
\text { We have achieved competitiveness much faster than had we 'gone it alone'. } \\
\text { (Source: New scales) }\end{array}$ & $\begin{array}{l}0.80 \\
0.92 \\
0.91\end{array}$ \\
\hline
\end{tabular}

\section{Descriptive Characteristics of Respondents}

Median size: 6 full-time employees; Median age: 2.5 years: Median turnover in previous 12-month period: GBP 400,000 .

\footnotetext{
${ }^{a}$ Measurement scales were anchored at 'strongly disagree' (1) and ‘strongly agree' (7), such that increasing agreement represents increasing magnitude in the measures.

${ }^{\mathrm{b}}$ Pearson correlation coefficients. All correlations are significant at the 0.001 level (two-tailed).
} 
Table 2: Final Cluster Centres of Incubation Outcome Groups

\begin{tabular}{|c|c|c|c|c|}
\hline & \multicolumn{4}{|c|}{ Cluster (Incubation Outcome Group) Means ${ }^{\text {b }}$} \\
\hline $\begin{array}{l}\text { Matrix } \\
\text { Dimensions }^{\text {a }}\end{array}$ & $\begin{array}{c}1 \\
\text { Enclosed } \\
\text { Incubation } \\
\text { (EI) }\end{array}$ & $\begin{array}{c}2 \\
\text { Specialised } \\
\text { Incubation (SI) }\end{array}$ & $\begin{array}{c}3 \\
\text { Community } \\
\text { Incubation } \\
\text { (CI) }\end{array}$ & $\begin{array}{c}4 \\
\text { Dynamic } \\
\text { Incubation (DI) }\end{array}$ \\
\hline RESPOOL & 1.58 & 3.80 & 2.79 & 5.01 \\
\hline SN_INV & 1.73 & 2.90 & 4.09 & 5.29 \\
\hline No. of cases & 70 & 47 & 48 & 37 \\
\hline
\end{tabular}

${ }^{\mathrm{a}}$ RESPOOL = resource pooling activity; SN_INV = strategic network involvement.

b Measurement scales were anchored at 'strongly disagree' (1) and 'strongly agree' (7), such that increasing agreement represents increasing magnitude in the measures. 
Table 3: Incubation Outcome Type Group Differences: Multivariate ${ }^{a}$ and Univariate Differences

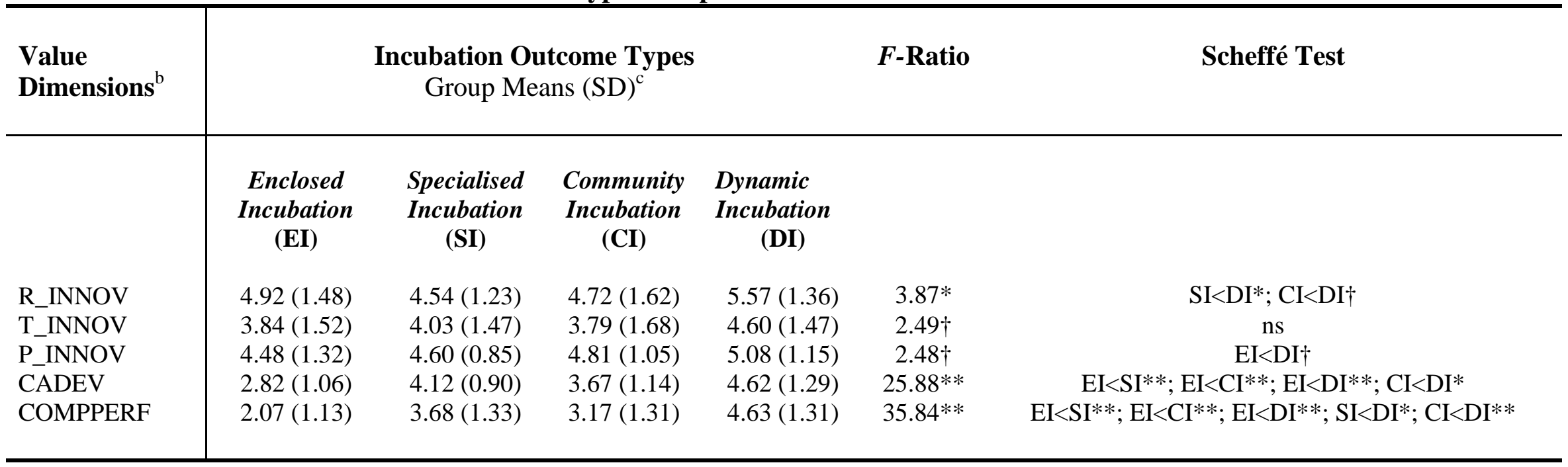

${ }^{a}$ MANOVA: Wilks' Lambda $=0.54 ; F=8.48 ; p \leq 0.001$.

${ }^{\mathrm{b}} \mathrm{R} \_\mathrm{INNOV}=$ radical innovation; $\mathrm{T} \_\mathrm{INNOV}=$ technical innovation; $\mathrm{P} \_\mathrm{INNOV}=$ product innovation; $\mathrm{CADEV}=$ competitive ability development; COMPERF = competitive performance.

'Measurement scales were anchored at 'strongly disagree' (1) and 'strongly agree' (7).

** $p \leq 0.01 ; * p \leq 0.05 ; \dagger p \leq 0.1 ;$ ns $=$ not significant. 
Figure 1: Value Stimulant Matrix

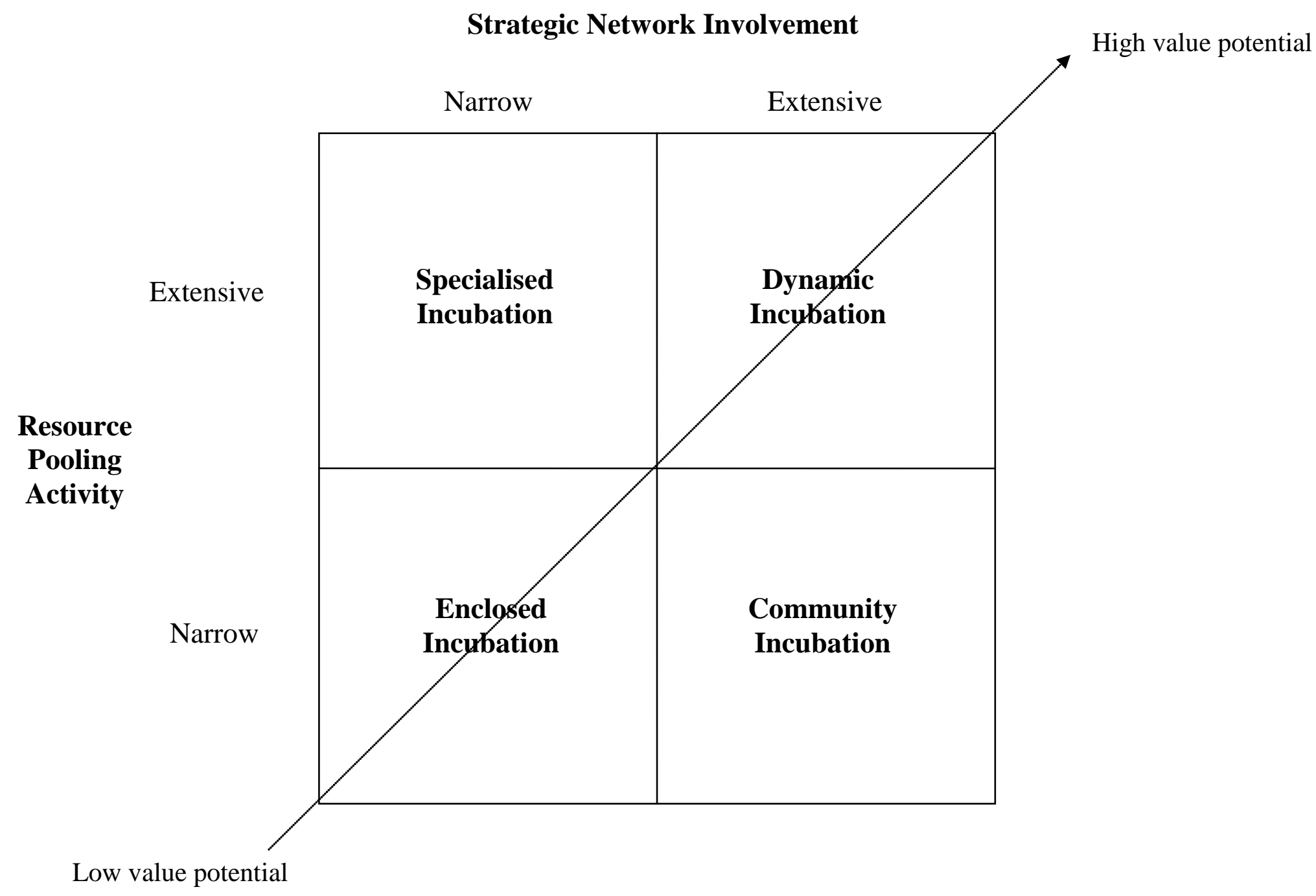




\section{REFERENCES}

1 J. Freeman, G.R. Carroll and M.T. Hannan, The liability of newness: Age dependency in organizational death rates, American Sociological Review, 48(5), 692-710 (1983).

2 S.M. Hackett and D.M. Dilts, A systematic review of business incubation research, Journal of Technology Transfer, 29, 55-82 (2004); L. Peters, M. Rice and M. Sundararajan, The role of incubators in the entrepreneurial process, Journal of Technology Transfer, 29, 83-91 (2004).

${ }^{3}$ For example, S.A. Mian, Assessing and managing the university technology business incubator: An integrative framework, Journal of Business Venturing, 12, 251-285 (1997).

${ }^{4}$ M.T. Hansen, H.W. Chesbrough, N. Nohria and D.N. Sull, Networked incubators: Hothouses of the new economy, Harvard Business Review, 78(5), 75-84 (2000).

${ }^{5}$ A. Kambil, E.D. Eselius and K.A. Monteiro, Fast venturing: The quick way to start web businesses, Sloan Management Review, 41(4), 55-67 (2000).

${ }^{6}$ R.W. Smilor, Managing the incubator system: Critical success factors to accelerate new company development, IEEE Transactions on Engineering Management, 34(3), 146-155 (1987); Mian, 1997, ibid.

7 Hansen et al., 2000, ibid.

${ }^{8}$ Hackett and Dilts, 2004, ibid; M.P. Rice, Co-production of business assistance in business incubators: An exploratory study, Journal of Business Venturing, 17, 163-187 (2002).

${ }_{9}$ R. Gulati, N. Nohria and A. Zaheer, Strategic networks, Strategic Management Journal, 21, 203215 (2000).

10 M.A. Hitt, R.D. Ireland, S.M. Camp, and D.L. Sexton, Strategic entrepreneurship: Entrepreneurial strategies for wealth creation, Strategic Management Journal, 22(Special Issue), 479-491 (2001).

11 R.D. Ireland, M.A. Hitt, and D.G. Sirmon, A model of Strategic Entrepreneurship: The construct and its dimensions, Journal of Management, 29(6), 963-989 (2003).

12 J.S. Coleman, Social capital and the creation of human capital, American Journal of Sociology, 94, 95-120 (1988); B.R. Koka and J.E. Prescott, Strategic alliances as social capital: A multidimensional view, Strategic Management Journal, 23(9), 795-816 (2002); S. Rodan and C. Galunic, More than network structure: How knowledge heterogeneity influences managerial performance and innovativeness, Strategic Management Journal, 25(6), 541-562 (2004).

${ }^{13}$ R.S. Burt, Structural Holes: The Social Structure of Competition, Harvard University Press: Cambridge, MA (1992); J. Nahapiet and S. Ghoshal, Social capital, intellectual capital, and the organizational advantage, Academy of Management Review, 23, 242-266 (1998); W. Tsai and S. Ghoshal, Social capital and value creation: The role of intrafirm networks, Academy of Management Journal, 41, 464-476 (1998).

14 J.H. Dyer and H. Singh, The relational view: cooperative strategy and sources of interorganizational competitive advantage, Academy of Management Review, 23, 660-679 (1998).

${ }_{15}$ Nahapiet and Ghoshal, 1998, ibid.

16 R.M Grant and C. Baden-Fuller, A knowledge accessing theory of strategic alliances, Journal of Management Studies, 41(1), 61-84 (2004).

17 L.P. Bucklin and S. Sengupta, Organizing successful co-marketing alliances, Journal of Marketing, 57(2), 32-46 (1993); J.H. Dyer, P. Kale and H. Singh, How to make strategic alliances work, Sloan Management Review, 42(4), 37-43 (2001); R. Larsson, L. Bengtsson, K. Henriksson and J. Sparks, The interorganizational learning dilemma: Collective knowledge development in strategic alliances, Organization Science, 9(3), 285-305 (1998). 
18 R.W. Coff, D.C. Coff, and R. Eastvold, The knowledge-leveraging paradox: How to achieve scale without making knowledge imitable, Academy of Management Review, 31(2),p452-465 (2006).

${ }^{19}$ G.P. Huber, Organizational learning: The contributing processes and the literatures, Organization Science, 2(1), 88-115 (1991).

${ }^{20}$ M.P. Koza and A.Y. Lewin, The co-evolution of strategic alliances, Organization Science, 9(3), 255-264 (1998).

${ }^{21}$ J.G. March, Exploration and exploitation in organizational learning, Organization Science, 2(1), 71-97 (1991).

${ }^{22}$ For example, Dyer and Singh, 1998, ibid; Gulati et al., 2000, ibid; R.D. Ireland, M.A. Hitt and D. Vaidyanath, Alliance management as a source of competitive advantage, Journal of Management, 28(3), 413-446 (2002).

${ }^{23}$ H. Hâkansson and I. Snehota, Developing Relationships in Business Networks, London: Routledge (1995).

${ }^{24}$ B. McEvily and A. Zaheer, Bridging ties: A source of firm heterogeneity in competitive capabilities, Strategic Management Journal, 20, 1133-1156 (1999); B. Uzzi, The sources and consequences of embeddedness for the economic performance of organizations: The network effect, American Sociological Review, 61, 674-698 (1996).

${ }^{25}$ For example, Hansen et al., 2000, ibid; Kambil et al., 2000, ibid.

${ }^{26}$ J.M. Hite and W.S. Hesterly, The evolution of firm networks: From emergence to early growth of the firm, Strategic Management Journal, 22, 275-286; March, 1991, ibid.

${ }_{27} \mathrm{U}$. Andersson, M. Forsgren and U. Holm, The strategic impact of external networks: Subsidiary performance and competence development in the multinational corporation, Strategic Management Journal, 23, 979-996 (2002); D.J. Kelley and M.P. Rice, Advantage beyond founding: The strategic use of technologies, Journal of Business Venturing, 17, 41-57 (2002); W. Shan, G. Walker and B. Kogut, Interfirm cooperation and startup innovation in the biotechnology industry, Strategic Management Journal, 15, 387-394 (1994); M. Sarkar, R. Echambadi, S.T. Cavusgil and P.S. Aulakh, The influence of complementarity, compatibility, and relationship capital on alliance performance, Journal of the Academy of Marketing Science, 29, 358-373 (2001).

${ }^{28} \mathrm{~S}$. Chung, H. Singh and K. Lee, Complementarity, status similarity and social capital as drivers of alliance formation, Strategic Management Journal, 21, 1-22 (2000); Tsai and Ghoshal, 1998, ibid.

${ }^{29}$ F.T. Rothaermel and D.L. Deeds, Exploration and exploitation alliances in biotechnology: A system of new product development, Strategic Management Journal, 25, 201-221 (2004).

${ }^{30}$ E.M. Rodgers, Diffusion of Innovations, $4^{\text {th }}$ Edition, New York: The Free Press (1995); A. Zaheer and G.G. Bell, Benefiting from network position: Firm capabilities, structural holes, and performance, Strategic Management Journal, 26, 809-825 (2005).

${ }^{31} \mathrm{D}$. Obstfeld, Social networks, the tertius iungens orientation, and involvement in innovation, Administrative Science Quarterly, 50(1), 100-130 (2005).

${ }_{32}$ G.T. Doran and J. Gunn, Decision making in high-tech firms: Perspectives of three executives, Business Horizons, 45(November-December), 7-16 (2002); R.E. Morgan and C.A. Strong, Business performance and dimensions of strategic orientation, Journal of Business Research, 56, 163-176 (2003); K. Traynor and S. Traynor, A comparison of marketing approaches used by high-tech firms: 1985 versus 2001, Industrial Marketing Management, 33, 457-461 (2004). 
${ }^{33}$ D.A. Dillman, Mail and Internet Surveys: The Tailored Design Method, $2^{\text {nd }}$ Edition, New York: John Wiley \& Sons (2000).

${ }^{34}$ C.S. Cycyota and D.A. Harrison, Enhancing survey response rates at the executive level: Are employee- or consumer-level techniques effective?, Journal of Management, 28(2), 151-176 (2002); G.P. Huber and R. Power, Retrospective reports of strategic-level managers: Guidelines for increasing their accuracy, Strategic Management Journal, 6, 171-180 (1985); D. Norburn, The Chief Executive: A breed apart, Strategic Management Journal, 10, 1-15 (1989); C. Stubbart, Managerial cognition: A missing link in strategic management research, Journal of Management Studies, 26, 325-347 (1989).

35 P.M. Podsakoff and D.W. Organ, Self-reports in organizational research: Problems and prospects, Journal of Management, 21, 913-929 (1986); P.M. Podsakoff , S.B. MacKenzie, J-Y. Lee and N.P. Podsakoff, Common method biases in behavioural research: A critical review of the literature and recommended remedies, Journal of Applied Psychology, 88, 879-903 (2003).

36 J.S. Armstrong and T.S. Overton, Estimating non-response bias in mail surveys, Journal of Marketing Research, 14(3), 396-402 (1977).

${ }^{37}$ H. Yli-Renko, E. Autio and H.J. Sapienza, Social capital, knowledge acquisition, and knowledge exploitation in young technology-based firms, Strategic Management Journal, 22, 587-613 (2001).

38 Hansen et al., 2000, ibid; M. Sarkar, R. Echambadi, S.T. Cavusgil and P.S. Aulakh, P.S, The influence of complementarity, compatibility, and relationship capital on alliance performance, Journal of the Academy of Marketing Science, 29, 358-373 (2001); E. Sivadas and F.R. Dwyer, An examination of organizational factors influencing new product success in internal and alliance-based processes, Journal of Marketing, 64(1), 31-49 (2000).

39 Hansen et al., 2000, ibid; McEvily and Zaheer, 1999, ibid; Sarkar et al., 2001, ibid.

40 R. Garcia and R. Calantone, A critical look at technological innovation typology and innovativeness terminology: A literature review, Journal of Product Innovation Management, 19, 110-132 (2002); A. Rindfleisch and C. Moorman, The acquisition and utilization of information in new product alliances: A strength-of-ties perspective, Journal of Marketing, 65(2), 1-18 (2001); X.M. Song and M.E. Parry, A cross-national comparative study of new product development processes: Japan and the United States, Journal of Marketing, 61(2), 118 (1997).

${ }^{41}$ L.J. Cronbach, Coefficient alpha and the internal structure of tests, Psychometrika, 16, 297-334 (1951); J.C. Nunnally, Psychometric Theory, 2nd Edition, New York: McGraw-Hill (1978).

42 J.F. Hair, Jr., R.E. Anderson, R.L. Tatham, and W.C. Black, Multivariate Data Analysis, Upper Saddle River, NJ: Prentice-Hall (1998); D.J. Ketchen and C.L. Shook, The application of cluster analysis in strategic management research, Strategic Management Journal, 17(6), 441-458 (1996); see next reference too.

43 For example, M.S. Aldenderfer and R.K. Blashfield, Cluster Analysis, Newbury Park, CA: Sage Publications (1984); Ketchen and Shook, 1996, ibid; G. Punj and D.W. Stewart, Cluster analysis in marketing research: Review and suggestions for future research, Journal of Marketing Research, 20(May), 134-148 (1983); R. Speed, Maximising the potential of strategic typologies for marketing strategy research, Journal of Strategic Marketing, 1, 171-188 (1993); J.H. Ward, Hierarchical grouping to optimize an objective function, Journal of the American Statistical Association, 58(March), 236-244 (1963). 